\author{
Jan Bakker \\ Tim C. Jansen
}

\title{
Don't take vitals, take a lactate
}

Received: 19 March 2007

Accepted: 4 April 2007

Published online: 6 July 2007

(C) Springer-Verlag 2007

This editorial refers to the article available at: http://dx.doi.org/10.1007/s00134-007-0680-5.

J. Bakker (汭 · T. C. Jansen

Erasmus MC University Medical Centre, Department of Intensive Care, Room Hs 320 ,

P.O. Box 2040, 3000 CA Rotterdam, The Netherlands

e-mail: jan.bakker@erasmusmc.nl

The resident internal medicine called from the Emergency Department (ED). "Can you please come and see my patient, I think he is becoming septic and needs admission to intensive care". In the ED we found a confused older patient with an oxygen mask who was clearly dyspnoeic, the urinary catheter was filled with a dark brown fluid, the collecting bag was empty. The resident reported that he admitted the patient $4 \mathrm{~h}$ earlier as he suspected pneumonia. On admission the patient was hypoxic but this clearly improved with the supplemental oxygen. The resident was still waiting for all the laboratory results and the chest $\mathrm{X}$-ray. However, now that the patient had developed hypotension he thought the patient was clearly at risk and intensive care admission was required. When we asked why he had not called us earlier, he replied that he intended to admit the patient to the general ward as he was haemodynamically stable and oxygenation had improved on supplemental oxygen so intensive care admission was not required. When reviewing the blood sample that was drawn $30 \mathrm{~min}$ following presentation, besides hypoxaemia, an increased lactate level of $4.6 \mathrm{mmol} / \mathrm{l}$ was present. The resident pointed out that hyperlactataemia in sepsis is not related to tissue hypoxia but rather is a marker of increased aerobic metabolism. Therefore he thought there was no need to react to this hyperlactataemia. Where did this resident go wrong?

Increased blood lactate levels in critically ill patients are generally associated with increased morbidity and mortality $[1,2]$. Even haemodynamically stable patients with raised lactate levels, a condition referred to as compensated shock, are at increased risk of dying $[3,4]$. This not only applies to patients admitted to the intensive care unit; also early in the course of illness, increased blood lactate levels are related to increased morbidity and mortality. In a study published in this issue of Intensive Care Medicine, Howell et al. [5] evaluated the prognostic value of one single venous lactate measurement shortly after admission to the ED in patients with clinically suspected infection. Their study is a follow-up on a preliminary report [6], where they did not take into account possible confounding factors such as co-morbidities and vital signs. In the current prospective observational cohort study $(n=1,287)$, the authors constructed a multivariate model, controlling for age, blood pressure, presence of malignancy, platelet count and blood urea nitrogen level. They showed that venous lactate predicted 28day in-hospital mortality. The predictive power of the lactate level was independent of blood pressure and covariates. In patients with normal blood pressure, increased blood lactate levels $(>4.0 \mathrm{mmol} / \mathrm{l})$ were associated with a ten times higher mortality rate than normal lactate levels (mortality 26.5\%). Others have reported similar results in other patient populations. Lavery et al. [7] measured venous lactate within 10 min following admission to the ED in 375 trauma patients. This study showed that an increased lactate level $(>2.0 \mathrm{mmol} / \mathrm{l})$ was a better predictor of morbidity and mortality than physiological triage criteria (composed of heart rate, blood pressure, Glasgow coma scale and respiratory rate). Rivers et al. [8] also showed that traditional physiological variables did not adequately determine septic patients at risk of increased 
mortality. However, when Hucker et al. [9] included all patients admitted to the hospital following presentation at the ED, neither clinical measures nor venous lactate could adequately predict hospital mortality or length of hospital stay. The short-term evolution in blood lactate has also been associated with mortality. In intensive care patients with circulatory shock, Vincent et al. [10] showed that 20 min following fluid resuscitation, non-survivors could already be distinguished from the surviving patients. In the ED, Nguyen et al. [11] observed the evolution of serial lactate levels in patients with severe sepsis during the first $6 \mathrm{~h}$ of treatment. In this study, a 10\% decrease in lactate levels during the 6-h study period was related to an $11 \%$ decrease in the likelihood of mortality. Furthermore, 29\% of the patients that did not show a decrease in lactate levels during the study did not have hypotension, where the mortality in this group still exceeded 55\% [11]. As venous [7, 12] and capillary [13] blood can be used to reflect arterial blood lactate levels with a turnaround time of less than 2 min [13], the clinician can rapidly identify a group of patients that, irrespective of their haemodynamic stability, has an increased risk of morbidity and mortality. This thus represents a faster and more reliable (independent of inter- and intra-observer variations) severity scoring than commonly used triage and scoring systems.

Two important questions remain, not so much to assess the use of lactate levels as a risk assessment tool, but more to decide what therapeutic measures should be taken when lactate levels are increased. First, why do patients with more often die than patients without increased lactate levels? A systemic imbalance between oxygen delivery $\left(\mathrm{DO}_{2}\right)$ and demand causes lactate levels to sharply rise, both in various experimental [14] and in clinical [15] conditions. Increased lactate levels have thus long been used to reflect the presence of tissue hypoxia. Hypoxia results in cell death and thus, if not resolved, leads to organ failure. Increased lactate levels and the duration of hyperlactataemia have indeed been associated with the level of organ failure in patients with septic shock [16]. However, besides this anaerobic mechanism, aerobic processes are also known to raise lactate levels in critically ill patients. First, increased aerobic glycolysis by cytokine-mediated cellular uptake of glucose [17] or by catecholamine-stimulated Na-K pump hyperactivity [18] can result in increased pyruvate production that exceeds the capacity of the pyruvate dehydrogenase enzyme complex (PDH) and thus results in increased lactate levels by mass effect. Second, in sepsis, PDH dysfunction has been reported [19]. Third, the lung is known to produce lactate, probably marking metabolic adaptations in response to inflammatory mediators rather than tissue hypoxia [20, 21]. Finally, reduced clearance of lactate will result in increased levels even when lactate production is not increased. In hemodynamically stable patients with sepsis, impaired clearance has been associated with increased lactate levels [22]. Second, what therapeutic actions should be taken in patients with increased blood lactate levels to improve their prognosis? From earlier studies in the 1980s and 1990s it is clear that correcting lactate levels itself will not improve outcome of critically ill patients [23, 24]. As oxygen supply dependency, as a marker of tissue hypoxia and increased lactate levels, is present in the early phase of critical illness [25], it seems logical to improve tissue oxygen delivery in patients with increased lactate levels. Several studies aimed at improving tissue oxygenation in patients with increased lactate levels have been associated with an improvement in morbidity and mortality $[3,8,26,27]$. Furthermore, high lactate levels may reflect microcirculatory derangement, hampering oxygen utilization at the tissue level [28]. This is illustrated by the observation that improving capillary perfusion has been shown to decrease lactate levels independent of changes in systemic haemodynamic variables [29]. However, randomized controlled trials in critically ill patients to prove this have not been performed. A recently started randomized controlled multi-centre trial, that is now halfway, is designed to evaluate the value of lactate level-guided therapy early in the course of critical illness (http://www.clinicaltrials.gov/ct/show/ NCT00270673?order=1).

However, increased lactate levels, as a marker of tissue hypoxia in critically ill patients, remain a matter of debate [30]. Given the many processes that may affect the ultimate concentration of lactate, both individual lactate levels and the change in level over time may well reflect the general homeostasis of the critically ill patient. The current study by Howell et al. [5] clearly shows that the use of a single measurement of venous lactate, that can be available rapidly following admission to the $\mathrm{ED}$, provides the clinician with better risk assessment, possibly with a clear direction to diagnosis and therapy, than vital signs. In the case presentation the resident could thus have diagnosed a severe disturbance in the homeostasis of his patient, despite the haemodynamic stability for the next few hours, 30 min following admission when the first lactate level became available. The intensivist could then perhaps have made a bigger impact on the outcome of this patient, who died several days following admission. 


\section{References}

1. Bakker J, Gris P, Coffernils M, Kahn RJ, Vincent JL (1996) Serial blood lactate levels can predict the development of multiple organ failure following septic shock. Am J Surg 171:221-226

2. Smith I, Kumar P, Molloy S, Rhodes A, Newman PJ, Grounds RM, Bennett ED (2001) Base excess and lactate as prognostic indicators for patients admitted to intensive care. Intensive Care Med 27:74-83

3. Blow O, Magliore L, Claridge JA, Butler K, Young JS (1999) The golden hour and the silver day: detection and correction of occult hypoperfusion within 24 hours improves outcome from major trauma. J Trauma 47:964-969

4. Meregalli A, Oliveira RP, Friedman G (2004) Occult hypoperfusion is associated with increased mortality in hemodynamically stable, high-risk, surgical patients. Crit Care 8:R60-R65

5. Howell M, Donnino M, Clardy $\mathrm{P}$, Talmor D, Shapiro N (2007) Occult hypoperfusion and mortality in patients with suspected infection. Intensive Care Med. DOI 10.1007/s00134-007-0680-5 (this issue)

6. Shapiro NI, Howell MD, Talmor D, Nathanson LA, Lisbon A, Wolfe RE, Weiss JW (2005) Serum lactate as a predictor of mortality in emergency department patients with infection. Ann Emerg Med 45:524-528

7. Lavery RF, Livingston DH, Tortella BJ, Sambol JT, Slomovitz BM, Siegel JH (2000) The utility of venous lactate to triage injured patients in the trauma center. J Am Coll Surg 190:656-664

8. Rivers E, Nguyen B, Havstad S, Ressler J, Muzzin A, Knoblich B, Peterson E, Tomlanovich M (2001) Early goal-directed therapy in the treatment of severe sepsis and septic shock. N Engl J Med 345:1368-1377

9. Hucker TR, Mitchell GP, Blake LD, Cheek E, Bewick V, Grocutt M, Forni LG, Venn RM (2005) Identifying the sick: can biochemical measurements be used to aid decision making on presentation to the accident and emergency department. Br J Anaesth 94:735-741

10. Vincent JL, Dufaye P, Berre J, Leeman M, Degaute J-P, Kahn RJ (1983) Serial lactate determinations during circulatory shock. Crit Care Med 11:449-451
11. Nguyen HB, Rivers EP, Knoblich BP, Jacobsen G, Muzzin A, Ressler JA, Tomlanovich MC (2004) Early lactate clearance is associated with improved outcome in severe sepsis and septic shock. Crit Care Med 32:1637-1642

12. Weil MH, Michaels S, Rackow EC (1987) Comparison of blood lactate concentrations in central venous, pulmonary artery, and arterial blood. Crit Care Med 15:489-490

13. Brinkert W, Rommes JH, Bakker J (1999) Lactate measurements in critically ill patients with a hand-held analyser. Intensive Care Med 25:966-969

14. De Backer D, Zhang H, Vincent JL (1995) Models to study the relation between oxygen consumption and oxygen delivery during an acute reduction in blood flow: comparison of balloon filling in the inferior vena cava, tamponade, and hemorrhage. Shock 4:107-112

15. Ronco JJ, Fenwick JC, Tweeddale MG, Wiggs BR, Phang PT, Cooper DJ, Cunningham KF, Russell JA, Walley KR (1993) Identification of the critical oxygen delivery for anaerobic metabolism in critically ill septic and nonseptic humans. JAMA 270:1724-1730

16. Bakker J, Gris P, Coffernils M, Kahn RJ, Vincent JL (1996) Serial blood lactate levels can predict the development of multiple organ failure following septic shock. Am J Surg 171:221-226

17. Haji-Michael PG, Ladriere L, Sener A, Vincent JL, Malaisse WJ (1999) Leukocyte glycolysis and lactate output in animal sepsis and ex vivo human blood. Metabolism 48:779-785

18. Levy B, Gibot S, Franck P, Cravoisy A, Bollaert PE (2005) Relation between muscle $\mathrm{Na}+\mathrm{K}+$ ATPase activity and raised lactate concentrations in septic shock: a prospective study. Lancet 365:871-875

19. Vary TC (1996) Sepsis-induced alterations in pyruvate dehydrogenase complex activity in rat skeletal muscle: effects on plasma lactate. Shock 6:89-94

20. Iscra F, Gullo A, Biolo G (2002) Bench-to-bedside review: lactate and the lung. Crit Care 6:327-329
21. Routsi C, Vincent JL, Bakker J, De Backer D, Lejeune P, dqHollander A, Le Clerc JL, Kahn RJ (1993) Relation between oxygen consumption and oxygen delivery in patients after cardiac surgery. Anesth Analg 77:1104-1110

22. Levraut J, Ciebiera JP, Chave S, Rabary O, Jambou P, Carles M, Grimaud D (1998) Mild hyperlactatemia in stable septic patients is due to impaired lactate clearance rather than overproduction. Am J Respir Crit Care Med 157:1021-1026

23. Stacpoole PW, Harman EM, Curry SH, Baumgartner TG, Misbin RI (1983) Treatment of lactic acidosis with dichloroacetate. N Engl J Med 309:390-396

24. Stacpoole PW, Wright EC, Baumgartner TG, Bersin RM, Buchalter S, Curry SH, Duncan CA, Harman EM, Henderson GN, Jenkinson S, et al. (1992) A controlled clinical trial of dichloroacetate for treatment of lactic acidosis in adults. The DichloroacetateLactic Acidosis Study Group. N Engl J Med 327:1564-1569

25. Friedman G, De Backer D, Shahla M, Vincent JL (1998) Oxygen supply dependency can characterize septic shock. Intensive Care Med 24:118-123

26. Polonen P, Ruokonen E, Hippelainen M, Poyhonen M, Takala J (2000) A prospective, randomized study of goal-oriented hemodynamic therapy in cardiac surgical patients. Anesth Analg 90:1052-1059

27. Rossi AF, Khan DM, Hannan R, Bolivar J, Zaidenweber M, Burke R (2005) Goal-directed medical therapy and point-of-care testing improve outcomes after congenital heart surgery. Intensive Care Med 31:98-104

28. Ince $C$ (2005) The microcirculation is the motor of sepsis. Crit Care (Suppl) 9(4):S13-19

29. De Backer D, Creteur J, Dubois MJ, Sakr Y, Koch M, Verdant C, Vincent JL (2006) The effects of dobutamine on microcirculatory alterations in patients with septic shock are independent of its systemic effects. Crit Care Med 34:403-408

30. James JH, Luchette FA, McCarter FD, Fischer JE (1999) Lactate is an unreliable indicator of tissue hypoxia in injury or sepsis. Lancet 354:505-508 